\title{
LA INTERPRETACIÓN DE UN DISCURSO PRESIDENCIAL DE LAURA CHINCHILLA MIRANDA: UNA LECTURA LINGÜÍSTICO-DISCURSIVA
}

\author{
Gabriela Cruz \\ Sara Pacchiarotti
}

\begin{abstract}
RESUMEN
Esta investigación pretende realizar un análisis de un discurso presidencial al relacionar algunas categorías de la gramática sistémico-funcional de Halliday (2004) con las funciones estratégicas del discurso político propuestas por Chilton y Schäffner (2006), con el fin de demostrar cómo la manipulación del discurso, el establecimiento de relaciones de poder, la representación de los actores y el encubrimiento de ciertos temas frente a otros se concretizan por medio de las escogencias lingüísticas a disposición de los hablantes.
\end{abstract}

Palabras clave: gramática sistémico-funcional, análisis del discurso politico, metafunciones, funciones estratégicas.

\begin{abstract}
This article seeks to analyze a presidential speech by relating certain categories of Halliday's (2004) systemic functional grammar to the strategic functions of political discourse proposed by Chilton and Schäffner (2006). The goal is to show how the manipulation of discourse, the establishment of relationships dictated by power, the representation of agents and the misrepresentation of certain issues compared to other are instantiated by the linguistic resources speakers can select.

Key words: systemic functional grammar, political discourse analysis, metafunctions, strategic functions.
\end{abstract}

\section{Introducción}

Según van Dijk (1997: 21) el acceso preferente al discurso y el control sobre el mismo son una manifestación directa del poder social o institucional que una determinada persona pueda tener. Los actores sociales de este tipo tienen un acceso preferencial al discurso y pueden emprender acciones que están vedadas a los demás.

ML. Gabriela Cruz Volio. Doctoranda en Lingüística Hispánica en la Universidad Johannes Gutenberg de Maguncia. Correo electrónico: aby.cruz@gmail.com

ML. Sara Pacchiarotti. Doctoranda en Lingüística en la Universidad de Oregon.

Correo electrónico: sara.claudiovna@gmail.com

Recepción: 09- 04- 2013

Aceptación: 11- 06- 2013 
Uno de los ejemplos a través del cual un actor social puede ejercer poder mediante el discurso lo constituye el discurso político. Ante el problema de la definición de político, se entenderán como actos políticos "those actions (linguistic or other) which involve power, or its inverse, resistance" (Chilton y Schäffner 2006: 311). Siguiendo los planteamientos austinianos, Chilton y Shäffner (2006) proponen la noción de funciones estratégicas (strategic functions) como un nivel intermediario entre las situaciones y procesos políticos y los niveles de organización del discurso. Las funciones propuestas por los autores son: (i) coerción y resistencia; (ii) legitimación y deslegitimación; y (iii) representación y tergiversación ${ }^{1}$. Según los autores, al enlazar las funciones estratégicas con el análisis lingüístico de textos y discursos, deben tomarse en cuenta todos los niveles y aspectos del lenguaje, es decir, un análisis del discurso debe referirse tanto a la pragmática (interacción entre los hablantes y oyentes), la semántica (significados, estructura del léxico) y la sintaxis (organización interna de las oraciones). Así, la meta del análisis del discurso político, desde esta perspectiva, sería el establecimiento de relaciones entre estos niveles y las tres funciones estratégicas antes mencionadas. Como se demostrará, el análisis lingüístico de un discurso político demuestra cómo la estructura del lenguaje es reflejo de la manipulación ideológica de los actores sociales e instrumento para la implementación de las funciones estratégicas del discurso.

Se analizará el discurso de la Presidenta de la República de Costa Rica, Laura Chinchilla Miranda, en el Debate General de la Asamblea General de las Naciones Unidas el 23 de setiembre de 2010, considerando algunas categorías de la gramática sistémicofuncional de Halliday (2004). Los resultados del análisis lingüístico se utilizarán como prueba para demostrar de qué forma las estructuras lingüísticas permiten concretizar las funciones estratégicas de los discursos de poder propuestas por Chilton y Schäffner (2006). Además, de manera complementaria, se buscará en el texto la presencia de las esquinas del cuadrado ideológico propuesto por van Dijk.

La escogencia de la teoría sistémico-funcional para el análisis lingüístico se debe al fuerte matiz semiótico que la caracteriza. La teoría sistémico-funcional no enfrenta cuestiones meramente formales sino que abre paso también a consideraciones de carácter semántico, semiótico, pragmático y social, con lo cual se contribuiría significativamente a la descripción de los recursos lingüísticos como sistema de concreción de transmisión de ideología, poder y manipulación en el discurso político.

La escogencia del discurso se debe a que este fue la primera intervención de la primera Presidenta de la República de Costa Rica ante las Naciones Unidas y a que ni este ni ningún otro discurso presidencial de Laura Chinchilla Miranda ha sido analizado hasta el momento desde la perspectiva del análisis del discurso político, ni desde un enfoque lingüístico. La única publicación que existe hasta el momento vierte sobre las relaciones entre la oferta electoral de la candidata Laura Chinchilla y la nueva realidad demográfica, social y sexual de Costa Rica (Flórez-Estrada 2010). La presente investigación constituiría un análisis exploratorio de los discursos de la Presidenta Laura Chinchilla Miranda.

\section{Marco Teórico}

\subsection{La perspectiva socio-semiótica del análisis gramatical sistémico-funcional}

Halliday (1973: 23), al retomar la noción de Malinowski según la cual la organización interna del lenguaje no es accidental, sostiene que es razonable pensar que el funcionamiento 
social del lenguaje se refleje en la estructura lingüística, es decir, en la organización interna del lenguaje como sistema. De forma directa y totalmente reversible, además, la organización interna del lenguaje natural puede ser explicada más apropiadamente, según el autor, a raíz de las funciones sociales por las que el lenguaje ha evolucionado y que desempeña en la vida del hombre social. En otras palabras, el lenguaje es como es por lo que se hace con él. Aunque la diversidad funcional en el lenguaje humano adulto sea inabarcable, ésta se reduce, en la gramática, a un conjunto relativamente restringido de componentes funcionales que son intrínsecos al lenguaje como sistema: las metafunciones, también definidas por Halliday como 'macro-funciones'. Las metafunciones representacional, interpersonal y textual constituyen reflejos lingüísticos abstractos de la multiplicidad de los usos sociales del lenguaje. En efecto, a causa de la variedad de los usos sociales del lenguaje, este sistema ha evolucionado en una 'gramática', en la que las opciones están organizadas en un número restringido de componentes que el hablante selecciona simultáneamente dependiendo del uso que esté haciendo del lenguaje.

Una cláusula en una determinada lengua es, por ende, la realización simultánea de los significados interpersonales, representacionales y textuales, en la que cualquier elemento suele tener más de una función estructural.

\subsection{La cláusula como mensaje: la metafunción textual}

En la metafunción textual, la cláusula cobra significado como mensaje, pues mediante ella se transmite información. Según Halliday (2004), la estructura del mensaje está conformada por el Tema y el Rema. El Tema es el elemento escogido por el hablante para "centrar" o "aterrizar" el mensaje por transmitir, el cual implica un modo de producir significado relacionado con la construcción del texto, pues al organizar el discurso los hablantes realizan escogencias sistémicas reflejadas en el orden de los elementos, y este orden será lo que refleja la elección temática. Si bien hay otros elementos que pueden preceder al Tema de la cláusula, Halliday únicamente considera Tema topical (topical Theme) al primer grupo nominal que cumpla una función en la estructura experiencial de la cláusula, el cual es realizado por un constituyente que codifica un participante, una circunstancia o un proceso.

\subsection{La cláusula como intercambio: la metafunción interpersonal}

La cláusula es un intercambio si se considera a partir de la metafunción interpersonal: desde esta perspectiva la cláusula se organiza en un evento interactivo que le proporciona al hablante y al oyente los recursos necesarios para establecer relaciones sociales mediante la asignación de roles discursivos y la expresión de juicios y actitudes (Halliday y Matthiessen 2006: 11). Cuando el lenguaje se utiliza para el intercambio de información, la cláusula se transforma en proposición. En una proposición el lenguaje es el medio y el fin del evento interactivo: el lenguaje se utiliza con el objetivo de intercambiar información codificada en lenguaje (negar, afirmar, contradecir, etc.). Cuando el lenguaje se utiliza para el intercambio de bienes y servicios, la cláusula se transforma en propuesta. En una propuesta el lenguaje es utilizado exclusivamente como medio y no como fin, pues lo que se requiere o se pide es algo que surge extralingüísticamente (nos encontramos en el ámbito de las órdenes, las ofertas, las recomendaciones, etc.).

El Modo es la estructura sintagmática interpersonal de la cláusula, que se compone de Sujeto^Finito. El Finito es el elemento que circunscribe la deixis interpersonal de una 
cláusula determinada y expresa: (i) tiempo primario, es decir pasado, presente o futuro en el momento de la enunciación; y (ii) modalidad. El Sujeto proporciona el resto de lo que se necesita para formar una proposición: algo en relación a lo que la proposición puede ser afirmada o negada.

\subsection{La cláusula como representación: la metafunción experiencial}

La metafunción experiencial revela no sólo el potencial del lenguaje para producir significado, sino también cómo los hablantes eligen expresarse a partir de una gama de opciones sistemáticas propias de la codificación estructural de cada lengua. Cabe destacar la importancia de que escoger un modo de decir algo implica no haberlo dicho de otro modo: ninguna escogencia es neutral. En cuanto a la configuración experiencial de la cláusula, esta incluye las categorías semánticas de un proceso que se desarrolla a través del tiempo, los participantes relacionados directamente con cada proceso y las circunstancias concomitantes. Mediante la codificación gramatical de estos factores, la cláusula toma sentido como una manera de organizar la percepción de la experiencia. En la organización de la experiencia, el proceso es el elemento principal dentro de la figura; mientras que los participantes, encargados de provocarlo y/o verse afectados por él, se relacionan directamente con este. Según la teoría sistémico-funcional, existen seis tipos de procesos: materiales, mentales, relacionales, conductuales, verbales y existenciales. Es de vital importancia mencionar que los límites entre estas categorías son necesariamente difusos y esto se ve reflejado en la codificación gramatical. Los participantes, por otro lado, dependen directamente del tipo de proceso con el que se encuentran relacionados.

\section{El análisis del discurso político desde la perspectiva de Chilton y Schäffner}

En cuanto a la relación entre discurso político y lingüística, Chilton y Schäffner arguyen que, no obstante el estudio del lenguaje no ha sido nunca un área central en las disciplinas académicas relacionadas con la política, algunos filósofos políticos han dejado en claro su conciencia sobre el asunto. A este propósito, los autores sostienen que:

\footnotetext{
Some philosophers -and here Descartes is the best known- have defined humans as essentially linguistic animals. Aristotle, on the other hand, famously defined humans as political animals. No doubt both definitions contain a germ of truth. What political discourse analysts would probably claim, if they were to think philosophically, would be that the one definition necessarily involves the other. It is surely the case that politics cannot be conducted without language, and it is also probably the case that the use of language in the constitution of social groups leads to what we could call 'politics' in a broad sense. ${ }^{2}(2006)$
}

El enfoque, obviamente no exclusivo, que proponen los autores para analizar el discurso político consiste en relacionar la sutileza de las estructuras del comportamiento lingüístico con lo que se entiende por 'política' o 'comportamiento político'. Definen como 'político/a' cualquier acción (lingüística o de otro tipo) que incluya el concepto de poder o su inverso, es decir, resistencia. Con base en esta premisa, especifican además que estas situaciones políticas se relacionan con los tipos de discurso propios de este género por medio de lo que ellos definen como funciones estratégicas (strategic functions).

Estas funciones estratégicas permiten a los analistas del discurso obviar las funciones lúdicas, informativas, etc., del discurso y centrarse en los elementos que contribuyen a los sucesos intuidos como políticos. Las funciones propuestas por Chilton y Shäffner (2006: 311-312) son: 
a. Coerción y resistencia. Ejemplos de esta función son los actos respaldados por sanciones (legales y físicas): órdenes, leyes, etc. Otras formas más solapadas de coerción lo constituyen actos que no son fácilmente percibidos por el receptor o que no puede evadir, como preguntas o respuestas espontáneas o responder a solicitudes. Los actores políticos suelen actuar coercitivamente por medio del discurso en la planeación de sus discursos, en el orden de prioridad con que se disponen los temas a tratar, en el posicionamiento del 'yo' y 'los otros' en relaciones específicas y en la presuposición de realidades que el oyente debe aceptar al menos provisionalmente para decodificar y procesar el mensaje.

b. Legitimación y deslegitimación. Esta función se encuentra ligada a la coerción, pues establece el derecho a ser obedecido (legitimación). Las razones del obedecimiento tienen que ser comunicadas lingüísticamente, de forma implícita o explícita. Entre las estrategias utilizadas se encuentran: argumentos acerca de los deseos de los votantes, principios ideológicos generales, proyección de un liderazgo carismático, alarde de sus logros y una auto-presentación positiva. La deslegitimación es la contraparte: los otros (extranjeros, oposición no oficial, oposición institucional, enemigos internos) tienen que ser presentados de manera negativa y las técnicas mayormente utilizadas son el uso de ideas de fronteras y diferencia, y el uso de actos de habla como insultar, culpar, acusar, reprochar, entre otros.

c. Representación y tergiversación. El control político incluye el control de la información, que por definición es una cuestión de control del discurso. Una forma de tergiversación consiste en "economizar la verdad", es decir, se provee información, pero esta es cuantitativamente inadecuada respecto a las necesidades o intereses de los oyentes. La manifestación más extrema de tergiversación es la simple mentira. El eufemismo tiene un efecto cognitivo de "desenfocar" o "difuminar" los referentes no deseados, sean objetos o acciones. Los significados implícitos (hipérboles, lítotes) y otros recursos semánticos (ironía, metáfora, metonimia) de varios tipos también son utilizados para desviar la atención de referentes problemáticos. Los autores indican que estas tres funciones estratégicas se relacionan estrechamente con funciones que se encuentran en nuestra vida social en general y no sólo en 'política'. Sin embargo, el análisis del comportamiento lingüístico en términos de estas tres funciones implica 'politizar' ese comportamiento. Cabe aquí reiterar que, desde la perspectiva de Chilton y Schäffner, el hecho de relacionar las funciones estratégicas con el análisis de textos implica tomar en consideración todos los niveles (pragmático, semántico y sintáctico) del lenguaje.

\section{Marco metodológico}

La presente investigación pretende utilizar cimientos de gramática sistémico-funcional y relacionarlos con conceptos y categorías del análisis del discurso político, siguiendo la perspectiva de análisis de textos políticos propuesta por Chilton y Schäffner (2006). La metodología consiste en el análisis de un texto político, que se llevará a cabo al vincular las categorías propuestas por Halliday (2004) para el análisis lingüístico con las de Chilton y Schäffner para el análisis de las funciones estratégicas del discurso. De esta manera, se demostrará cómo las estructuras lingüísticas en el micronivel del discurso son utilizadas para reflejar y comunicar ciertos patrones de manipulación y uso del poder en el macronivel del discurso político. Complementariamente, también se analizará la macroestructura del discurso en relación con los cuatro ejes del cuadrado ideológico propuesto por van Dijk (1997). 
La escogencia de un discurso presidencial ante la $\mathrm{ONU}^{3}$ se considera válida dado que Chilton y Schäffner (2006: 313) incluyen, en el segundo grupo de textos que pueden someterse a un análisis de este tipo, los siguientes: discursos de estado interno (cuestiones de política doméstica), discurso de inter-estado (políticas exteriores y diplomacia), discurso político interno (charlas de políticos, planeamientos y decisiones entre ellos) y discurso político externo (políticos que se comunican con el público). En cuanto a los niveles de análisis lingüístico, el nivel pragmático será cubierto por las metafunciones textual e interpersonal, y el nivel semántico y sintáctico por la metafunción experiencial.

\section{Análisis lingüístico-discursivo del Discurso de la Presidenta de la República de Costa Rica, Laura Chinchilla Miranda, en el Debate General de la Asamblea General de las Naciones Unidas el 23 de setiembre de 2010}

\subsection{La metafunción textual: escogencias de Tema marcado frente a Tema no marcado}

En español, el Tema no marcado en una cláusula declarativa es un Sujeto no interactuante o el verbo conjugado si el Sujeto lo constituye un pronombre. Cualquier otro elemento en posición temática, será una instancia de tema marcado. La Tabla 1 describe la aparición de Temas marcados/no marcados en cláusulas declarativas:

Tabla 1. Tema en cláusulas declarativas

\begin{tabular}{|c|c|c|c|}
\hline \multicolumn{4}{|c|}{ Cláusulas Declarativas } \\
\hline Temas no marcados & \multicolumn{3}{|c|}{ Temas marcados } \\
\hline 72 & \multicolumn{3}{|c|}{41} \\
\hline & $\begin{array}{c}\text { Tematización de } \\
\text { Circunstanciales }\end{array}$ & $\begin{array}{c}\text { Tematización de } \\
\text { Complemento }\end{array}$ & $\begin{array}{c}\text { Tematización de } \\
\text { Predicado }\end{array}$ \\
\hline Total 113 & 26 & 10 & 5 \\
\hline
\end{tabular}

Según Halliday (2004: 73) el tipo más usual de Tema marcado en cláusulas declarativas es un grupo adverbial o una frase preposicional, que funcionan como Adjuntos en la cláusula como intercambio y como Circunstanciales en la cláusula como representación. Efectivamente, en el discurso de la presidenta, de los 41 temas marcados en cláusulas declarativas, 26 constituyen una tematización de algún elemento circunstancial.

Por otro lado, el tipo más marcado de Tema en una cláusula declarativa es el Complemento. El Complemento es un elemento nominal que, siendo tal, puede potencialmente haber sido el Sujeto pero que no ha sido seleccionado como tal y que, sin embargo, es el elemento que se ha tematizado. Puesto que pudo haber sido el Sujeto, y en consecuencia, el Tema no marcado, tiene que haber una muy buena razón para que se convierta en un Complemento temático. En el discurso, se presentan diez casos de tematización del Complemento. De estos, seis topicalizan la concepción del 'nosotros' (nos inspiran / nos angustian / nos inquietan / nos llaman a la acción inmediata / nos indigna) y los restantes enfatizan la recurrencia de palabras típicas del campo semántico de la guerra (la paz, la batalla / la lucha / los (países) desarrollados). Esto reafirma nuevamente la necesidad de reforzar y resaltar a lo largo del discurso el hilo conductor del 'nosotros' y también enfatizar términos con connotaciones semánticas recurrentes en el campo de la metáfora bélica, preparando así un terreno fértil 
para el establecimiento de fronteras entre países desarrollados y en vía de desarrollo (quienes sufren más el peligro del narcotráfico). Desde el punto de vista de las estrategias discursivas es una instancia de cómo se concretiza lingüísticamente el concepto de coerción, puesto que la tematización establece el orden de los temas a tratar en el discurso y su aceptación, aunque fuese temporánea, por parte de los oyentes. Como se puede observar en los ejemplos anteriores, este discurso prioriza temáticamente las representaciones de los logros del "nosotros" y de los peligros a los que pueden estar sujetos. Esta tematización establece además los actores que se van a incluir en las funciones estratégicas de legitimación/deslegitimación, es decir, la construcción del nosotros y la otredad.

\subsection{La metafunción interpersonal en el discurso: las implicaciones ideológicas de las escogencias de Sujetos en el discurso de Laura Chinchilla}

En gramática sistémico-funcional, el Sistema de SUJETO/PERSONA marca las pautas que rigen la conversación o el discurso: cuando el intercambio es dialógico las opciones del Sistema son 'hablante' o 'destinatario', mientras que si no lo es, la opción del Sistema es, en la mayoría de los casos, 'no-interactuante', es decir un Sujeto no presente en la conversación o discurso.

Tabla 2. Clasificación de los tipos de persona

\begin{tabular}{|l|c|c|c|c|}
\hline \multicolumn{5}{|c|}{ PERSONA } \\
\hline total cláusulas & hablante & hablante + otros & no-interactuante & destinatario \\
\hline 115 & 8 & 28 & 77 & 2 \\
\hline sujeto explícito & 0 & 2 & 73 & 1 \\
\hline sujeto implícito & 8 & 26 & 4 & 1 \\
\hline
\end{tabular}

La Tabla 2 muestra la incidencia de los diferentes tipos de Sujeto con base en el total de cláusulas encontradas en el discurso. A partir de los datos obtenidos en cuanto al análisis de la manifestación del Sistema de Sujeto/Persona, cabe destacar que son muy reducidas las instancias en las que el Sujeto es el hablante, es decir, la primera persona singular. Las primeras dos manifestaciones de este rol de habla consisten en actos ceremoniosos con valor realizativo (tomo la palabra / saludo / hago un llamado urgente) típicos de este contexto de enunciación. Sucesivamente, la primera persona singular es usada para: (i) aclarar temas expuestos anteriormente (menciono lo anterior...); (ii) proponer acciones a ser tomadas por la comunidad internacional (propongo potenciar aún más los conceptos...); (iii) reafirmar la convicción/predisposición hacia algo (soy consciente de que... estoy convencida de que...).

La totalidad de estos actos son, según la clasificación propuesta por Searle, representativos, es decir, pertenecen al campo semántico de los verbos de hablar, afirmar, etc. Frente a un uso limitado de la opción hablante en el sistema de Sujeto Persona, mucho más consistente es la escogencia de la opción 'hablante+otros'. El uso del Sujeto de primera persona plural tiene un propósito discursivo significativamente distinto del de primera persona singular. En las primeras apariciones se nota una dicotomía entre la presentación de un escenario social de fondo positivo (podemos felicitarnos) vs negativo (nos inquietan / nos angustian). Sucesivamente el uso de la primera persona plural Sujeto sirve para describir las acciones positivas emprendidas por el gobierno de la Presidenta y también para impartir órdenes (actos de habla directivos) atenuadas por el uso de metáforas (debemos descorrer las cortinas de los prejuicios). 
Otro uso del plural de primera persona en el discurso es el que sirve para expresar la idea de 'nosotros' frente a un 'ellos' considerado como otredad con el objetivo de exponer los peligros que acechan al 'nosotros' (la narcoactividad) y la voluntad de actuar y rescatarse. El contraste entre el 'nosotros amenazado' frente a la otredad como 'culpable/responsable de la amenaza' también es reforzado por la escogencia de determinados sujetos no interactuantes que forman parte de un 'nosotros' inclusivo. Sucesivamente los actores de la otredad son incitados por medio de una orden a solucionar el problema padecido por el nosotros y a esto le sigue una reafirmación de la positividad del nosotros frente a la negatividad o ausencia de acción del 'ellos' y de la consecuente pretensión de beneficios o cursos de acción positivos para el nosotros en el futuro. La Tabla 3 ejemplifica las distintas partes en las que se divide el discurso y la manipulación que se desprende de ellas según los ejes del cuadrado ideológico propuesto por van Dijk (1997):

Tabla 3. Propósitos discursivos del uso del 'nosotros' en relación con los ejes del cuadrado ideológico

\begin{tabular}{|c|c|c|c|}
\hline \multicolumn{4}{|c|}{ Manipulación ideológica de la escogencia hablante+otros } \\
\hline & \begin{tabular}{|l|}
$\begin{array}{l}\text { Propósito } \\
\text { discursivo }\end{array}$ \\
\end{tabular} & $\begin{array}{l}\text { Eje del cuadrado } \\
\text { ideológico }\end{array}$ & Instancias \\
\hline $\begin{array}{c}\text { I } \\
\text { parte }\end{array}$ & $\begin{array}{l}\text { Dicotomía entre } \\
\text { escenario social } \\
\text { positivo vs negativo }\end{array}$ & $\begin{array}{l}\text { Magnificación de } \\
\text { la representación } \\
\text { positiva del nosotros }\end{array}$ & $\begin{array}{l}\text { Nos inspiran los jóvenes, trabajadores, campesinos } \\
\text { Podemos felicitarnos por los niños... } \\
\text { Nos angustian las madres jefas de hogar... } \\
\text { Nos inquietan los adultos mayores... }\end{array}$ \\
\hline $\begin{array}{c}\text { II } \\
\text { parte }\end{array}$ & $\begin{array}{l}\text { Presentación de } \\
\text { acciones positivas } \\
\text { emprendidas por } \\
\text { el gobierno de la } \\
\text { Presidenta }\end{array}$ & $\begin{array}{l}\text { Magnificación de } \\
\text { la representación } \\
\text { positiva del nosotros }\end{array}$ & $\begin{array}{l}\text { Impulsamos el crecimiento } \\
\text { Trabajamos por la estimulación } \\
\text { Debemos descorrer las cortinas de los prejuicios }\end{array}$ \\
\hline \multirow[t]{2}{*}{$\begin{array}{c}\text { III } \\
\text { parte }\end{array}$} & $\begin{array}{l}\text { Exposición de los } \\
\text { peligros que acechan } \\
\text { al 'nosotros' - } \\
\text { victimización }\end{array}$ & $\begin{array}{l}\text { Disminución de } \\
\text { la representación } \\
\text { negativa del nosotros }\end{array}$ & $\begin{array}{l}\text { Mi país y Centroamérica sufrimos.... } \\
\text { Estamos en riesgo... } \\
\text { Padecemos de un problema que no ha sido creado } \\
\text { por nosotros... } \\
\text { Nuestros sistemas de salud están casi desbordados... } \\
\text { Los jóvenes ven su futuro amenazado... }\end{array}$ \\
\hline & $\begin{array}{l}\text { Voluntad de } \\
\text { actuar y rescatarse } \\
\text { (incorporación de } \\
\text { metáfora bélica) }\end{array}$ & $\begin{array}{l}\text { Magnificación de } \\
\text { la representación } \\
\text { positiva del nosotros }\end{array}$ & $\begin{array}{l}\text { No vamos a fallarle } \\
\text { La lucha la estamos dando con energía } \\
\text { La batalla contra el narcotráfico solo podremos } \\
\text { ganarla... }\end{array}$ \\
\hline $\begin{array}{c}\text { IV } \\
\text { parte }\end{array}$ & $\begin{array}{l}\text { Incitación a que los } \\
\text { 'otros' solucionen } \\
\text { los problemas } \\
\text { padecidos por el } \\
\text { 'nosotros' }\end{array}$ & $\begin{array}{l}\text { Magnificación de } \\
\text { la representación } \\
\text { negativa del 'ellos' } \\
\text { (culpables/ } \\
\text { responsables de la } \\
\text { amenaza) }\end{array}$ & $\begin{array}{l}\text { Hago un llamado a los países que más contribuyen } \\
\text { al consumo de drogas... } \\
\text { Para que colaboren con quienes padecemos un } \\
\text { problema... } \\
\text { Que los organismos multilaterales aumenten su } \\
\text { actividad... }\end{array}$ \\
\hline $\begin{array}{c}\mathrm{V} \\
\text { parte }\end{array}$ & $\begin{array}{l}\text { Pretensión de cursos } \\
\text { de acción positivos } \\
\text { para el nosotros en } \\
\text { el futuro }\end{array}$ & $\begin{array}{l}\text { Magnificación de } \\
\text { la representación } \\
\text { positiva del nosotros }\end{array}$ & $\begin{array}{l}\text { Debemos beneficiarnos de esquemas innovadores } \\
\text { Estamos expectantes } \\
\text { Esperamos que todos asuman sus responsabilidades } \\
\text { En Costa Rica hemos asumido las nuestras } \\
\text { Necesitamos la ayuda del mundo }\end{array}$ \\
\hline
\end{tabular}


Es interesante observar el uso de metáforas atenuadoras en la minimización de lo negativo del 'nosotros' (debemos descorrer las cortinas de los prejuicios, los jóvenes ven su futuro amenazado) y de metáforas de recipiente que evocan el peligro del escape de líquidos como desastre en la victimización del 'nosotros' (nuestros sistemas de salud están casi desbordados). En relación con la función de representación y tergiversación, el uso de metáforas constituye un recurso lingüístico que cumple la función de difuminar referentes no deseados, tales como problemas en el sistema sanitario de un país, y asuntos de seguridad ciudadana relacionados con el narcotráfico que amenazan un futuro seguro para las generaciones venideras.

En varias ocasiones en el discurso, el uso de la primera persona plural es claramente inclusivo (Costa Rica y la ONU) o exclusivo (Costa Rica y sus ciudadanos sin incluir a la ONU) dependiendo de las colocaciones léxicas y del contenido que se está predicando y paralelamente, del intento de legitimación o deslegitimación. El uso del nosotros inclusivo se da en las siguientes situaciones discursivas: (i) exaltación de logros e indignación/angustia por las condiciones de la humanidad; (ii) órdenes/acciones a seguir para el mejoramiento de la situación; (iii) referencia a actos ceremoniosos globales; (iv) presentación de deberes/ responsabilidades. El uso del nosotros exclusivo se encuentra en los siguientes contextos: (i) despliegue de creencias/voluntad ejemplares por parte de Costa Rica; (ii) presentación de los logros individuales; (iii) presentación de peligros/riesgos de padecimiento o sufrimiento; (iv) exaltación de la participación activa en la lucha/batalla; (v) manifestación de expectativas.

La escogencia lingüística de persona (inclusiva/exclusiva) en el micronivel del texto se utiliza para establecer los lindes de legitimación y deslegitimación. En el caso de la deslegitimación, el nosotros inclusivo se usa como estrategia discursiva para mitigar actos de habla directivos (órdenes) que amenazan directamente la libertad de acción y el territorio de las entidades o países a los que van dirigidos (véase más arriba ii y iv) y sólo periféricamente se emplea esta escogencia en el sistema de persona para exaltar los logros alcanzados, lo cual representa otra estrategia mitigadora de acompañamiento de actos amenazantes. Nótese además que los directivos son la realización más evidente de la función estratégica de coerción. En el caso de la legitimación, la escogencia lingüística del nosotros exclusivo marca de forma contundente la voluntad, por parte de la Presidenta, de construir una autopresentación positiva de Costa Rica, haciendo hincapié en logros, principios morales, y por ende, un liderazgo carismático. Según Chilton y Schäffner, una de las principales maneras en las que los políticos se posicionan a sí mismos y a otros en relación con sus partidos, sus gobiernos y su nación es por medio del uso de los pronombres nosotros/nuestro (2006: 317).

Por lo que se refiere a los Sujetos no interactuantes, cabe destacar que en la construcción de la legitimación cooperan elementos lingüísticos en diferentes niveles de análisis: el uso de ciertas formas de tratamiento (nosotros inclusivo/exclusivo) se da en concomitancia con la escogencia de lexemas significativos desde un punto de vista semántico. Por ejemplo, en el fortalecimiento de la representación positiva del 'nosotros', abundan sustantivos abstractos con fuertes connotaciones positivas (el éxito de nuestra gestión global, el crecimiento económico, la apertura comercial, la transparencia política, la buena gobernanza global, el respeto al derecho internacional y a los organismos multilaterales, la responsabilidad y el liderazgo constructivos), aunados a la presencia de dos referentes concretos: Costa Rica y mi Gobierno. Vale la pena mencionar esto, porque la referencia a Costa Rica y al gobierno 
de Laura Chinchilla no ocurre a lo largo del texto de forma indiscriminada, sino sólo cuando el discurso vierte sobre la función de legitimación, es decir, en el caso anteriormente mencionado de autopresentación positiva y en la victimización del 'nosotros'. En este último caso, Costa Rica, mi gobierno y nuestro pueblo aparecen a la par de connotaciones léxicas diametralmente opuestas a las descritas anteriormente: tantos países (dilapidan recursos en armas), la comunidad internacional (incapaz), los países que más contribuyen al consumo de drogas, la narcoactividad, la violencia, la adaptación de la ONU a los retos de gobernanza global, los grandes países contaminantes y emisores de carbono. Contrariamente a los ejemplos anteriores, aquí se presentan sustantivos concretos (países) y con matices negativos o peyorativos. Las escogencias léxicas en este sentido son significativas también por las inferencias que se desprenden a partir de los lexemas insertados en el discurso cuando se quiere crear un escenario trágico que oprime al país de la Presidenta que, por lo visto, no es responsable sino víctima de todos estos acontecimientos. En otras palabras, tal y como se presenta el discurso, los oyentes asumen tácitamente que Costa Rica no dilapida recursos en armas, no contribuye significativamente ni al consumo de drogas, ni a la narcoactividad ni a la violencia y, siendo un país tan pequeño, no contamina igual que los países más grandes, sino que sufre todos estos procesos de los cuales no es, en ninguna medida responsable o co-responsable.

\subsection{La metafunción experiencial y la construcción metafórica del discurso}

En la gramática sistémico-funcional, el proceso es el elemento central de la figura y, según su tipo, ya sea material, mental, racional, verbal, conductual o existencial, determinará la clase de cláusula. Los tres tipos de procesos que más aparecen en lenguas como el español y el inglés son los materiales, mentales y relacionales y, de hecho, son estos los que predominan en el discurso analizado en este trabajo, como puede observarse en la Tabla 4:

Tabla 4. Comparación de los porcentajes de las cláusulas según los 4 tipos de procesos recurrentes en el texto

\begin{tabular}{|c|c|c|}
\hline TIPO DE PROCESO & número de cláusulas & porcentaje \\
\hline material & 45 & $39 \%$ \\
\hline relacional & 41 & $36 \%$ \\
\hline mental & 19 & $17 \%$ \\
\hline verbal & 9 & $8 \%$ \\
\hline Total de cláusulas & 114 & $100 \%$ \\
\hline
\end{tabular}

Las cláusulas de diferentes tipos de procesos hacen contribuciones distintas a la construcción de la experiencia en cada texto. El discurso de la Presidenta de la República de Costa Rica es experiencialmente variado, aunque las cláusulas materiales y relacionales son las que más aparecen. Precisamente, parte del matiz de un texto, y también del registro al que pertenece (en el caso de este análisis se trata de un registro político), reside en la mezcla de procesos que se da en él. Por ejemplo, en el discurso analizado, Laura Chinchilla, después de saludar a los destinarios, continúa con una serie de cláusulas que representan procesos mentales ${ }^{4}$, señalados con negrita: 
(1) En este momento, alrededor del mundo, esos valores y los compromisos que implican florecen, pero también sufren.

[...] Nos inspiran los jóvenes, trabajadores y campesinos con oportunidades de vida digna; $[\ldots]$

Pero nos angustian las madres jefas de hogar que apenas pueden alimentar a sus hijos. Nos inquietan los adultos mayores que envejecen con privaciones y en soledad; [...]

Al respecto, se puede observar aquí cómo la tematización, la escogencia de la primera persona plural inclusiva y el uso de cláusulas mentales son los recursos lingüísticos utilizados en el discurso para afianzar la función estratégica de legitimación. En cualquier discurso, la mezcla de tipos de procesos que recurren en él cambia el curso del desarrollo del contenido. Es decir, las cláusulas mentales, al referirse a eventos propios de la conciencia de cada quien, se utilizan para expresar la intención del hablante, por lo cual es natural que aparezcan al inicio del discurso. Las cláusulas materiales, puesto que expresan sucesos y acciones, marcan el contenido del discurso. Sin embargo, en este discurso no parece que estuviera sucediendo o aconteciendo gran cosa, lo cual es significativo, dada la gran cantidad de procesos materiales que presenta el texto. A este hecho también contribuye la ocurrencia de tantas cláusulas relacionales, pues estas, encargadas nada más de establecer una relación entre dos entidades, no implican acontecimientos reales. A continuación, se hará una descripción de la relevancia e implicación que tienen los distintos tipos de procesos que predominan en el discurso de Laura Chinchilla ante la ONU con el fin de demostrar cómo su escogencia es de fundamental importancia en la transmisión de las funciones estratégicas de legitimación/deslegitimación y representación/tergiversación.

\subsubsection{La construcción de cláusulas materiales en el discurso}

De acuerdo con Halliday (2004), las cláusulas materiales se refieren a procesos que tienen que ver con acciones o acontecimientos, pero no representan necesariamente eventos físicos y concretos, sino que también pueden representar hechos y sucesos de índole más abstracta. Puesto que este tipo de proceso implica un cambio en el estado de las cosas, el rol participante directamente asociado con las cláusulas materiales es el Actor, quien se encarga de provocar tal cambio. Estas cláusulas describen un proceso que se desarrolla a través del tiempo, por lo cual es posible hacer dos distinciones de acuerdo con la extensión que este tenga. Si el evento provoca un cambio que sólo atañe al Actor mismo, entonces la cláusula material representa un suceso (cláusula intransitiva). Sin embargo, si el progreso del acontecimiento impacta de alguna manera a otro participante, entonces la cláusula material constituye una acción (cláusula transitiva). Este participante, a quien se dirige el Proceso, se denomina Meta.

Estas clausulas, las cuales construyen figuras de hacer y suceder, típicamente implican acciones y sucesos. Es decir, hechos que marcan un cambio en el estatus de las cosas, pues expresan la noción de que una entidad "hace" algo, hacia sí misma o hacia otra entidad. Entonces, ¿por qué son estas las cláusulas predominantes en un discurso más descriptivo que narrativo? ¿Por qué al leerlo queda la sensación de que no está pasando nada realmente, aunque la mayoría de las cláusulas sean materiales? En primer lugar, debe tomarse en cuenta el tipo de proceso material que está siendo representado en las cláusulas intransitivas, las cuales implicarían un cambio ocurrido en un solo participante: 
(2) al gobernanza comienza por el buen gobierno nacional

(3) u aporte llega a todos los confines del mundo

(4) el calentamiento global no espera

En los ejemplos anteriores, cuyos procesos están señalados con negrita, es evidente que aunque se trate de cláusulas materiales, los verbos no son prototípicamente materiales porque comenzar, llegar y avanzar y esperar no cambian de manera significativa al Actor, el cual aparece con cursiva, como sí lo hacen sucesos del tipo correr, jugar y volar. Nótese que el verbo comenzar, por ser inherentemente incoativo, no marca ninguna acción. Luego, el verbo llegar, más que indicar movimiento, se refiere a una finalidad, por lo cual tampoco se puede decir que está ocurriendo algo. El verbo del ejemplo 4, esperar, por su propio significado, tampoco es un verbo de acción. Otro ejemplo importante de una cláusula intransitiva que demuestra cómo este discurso, aparentemente lleno de hechos y sucesos, es más bien estático y nada concreto, es el siguiente:

\section{(5) la contaminación de cuencas hidrográficas avanza}

Al igualque los verbos señalados anteriormente, avanzar no es un verbo prototípicamente material. Además, es importante señalar que se trata de una construcción metafórica en la cual algo que no es humano se considera como algo humano (Lakoff y Johnson 1998). Sin embargo, el participante la contaminación de las cuencas hidrográficas, más que realizar la "acción" del verbo avanzar, es más bien quien atraviesa ese proceso o, para decirlo en términos metafóricos, lo sufre. En la construcción haría falta otro participante, el encargado de provocar el proceso. Astutamente, tal participante no es mencionado, de manera que parece que el único responsable del avance de la contaminación de las cuencas hidrográficas es la contaminación misma. En relación con las funciones estratégicas, nótese cómo el uso de cláusulas intransitivas "pseudo-materiales" es un recurso lingüístico que realiza la función de tergiversación, mediante la creación de actores inciertos y escurridizos cuando el discurso vierte sobre temas problemáticos como el calentamiento global, la contaminación y la necesidad de una mejor gobernanza global. Otro dato destacable es que el uso de la intransitividad en sí también contribuye a reforzar esta función estratégica. Según Chilton y Schäffner:

\footnotetext{
There is another premise that explains the prevalence of intransitivity [...]: that there is a 'natural' order of things and a 'natural' course of events. Thus, intransitive constructions encode the notion that the universe changes independently and also make it possible to avoid complex controversial issues of blame and responsibility. (2006: 324)
}

El segundo aspecto que debe considerarse es el nivel de transitividad de los verbos de cláusulas transitivas, como en los siguientes ejemplos:

(6) la violencia alcanza niveles nunca antes vistos

(7) asuman allí sus responsabilidades hacia la humanidad

(8) nos adherimos a los cinco puntos sobre el control de armamentos

(9) nuestro país impulsó y las Naciones Unidas apoyó una institución pionera y visionaria en la materia, la Universidad para la Paz

(10) celebramos con orgullo $\underline{\mathrm{su}}$ aniversario $^{5}$ 
De acuerdo con Givón (1984), el grado de transitividad de los verbos se da como en un continuum que tiene que ver con el grado de afectación del objeto: entre más afectado sea este, más alto será el nivel de transitividad de la cláusula. Si se analizan los ejemplos anteriores, en todos los casos puede observarse que los objetos (marcados con el subrayado), identificados con el participante Meta en la gramática sistémico-funcional, no están siendo realmente afectados por los procesos respectivos. Por lo tanto, tampoco estas cláusulas son prototípicamente materiales, pues no expresan un verdadero cambio ocurrido en el objeto. En otras palabras, las cláusulas transitivas son también, al igual que las intransitivas, "pseudomateriales", y como tales contribuyen a construir cierto nivel de abstracción y ausencia de verdaderos actores en la discusión de temas potencialmente conflictivos, como el aumento de los niveles de violencia y la toma de responsabilidades por parte de "culpables".

En los pocos casos que se han utilizado verbos típicamente materiales, se trata de construcciones metafóricas léxicas:

(11) la voluntad individual y colectiva, la responsabilidad y el liderazgo constructivos pueden romper obstáculos y trazar mejores caminos

(12) mientras tantos países dilapidan recursos en armas

(13) debemos descorrer las cortinas de los prejuicios que oscurecen la realidad

A partir de los ejemplos anteriores se puede observar nuevamente cómo el uso de significados implícitos construidos por medio de figuras retóricas como la metáfora cumplen con el propósito de alivianar temas que suponen el establecimiento de responsabilidades y culpables, en el marco de la función de tergiversación.

El tercer aspecto por considerar son los participantes en cuanto a su función en el sistema de PERSONA INTERACTUANTE (Figura 1) y su grado de abstracción. En la mayoría de estas cláusulas materiales, los actores son no interactuantes, es decir, que si hay alguien relacionado con un proceso que implica un cambio, son los otros:

(14) la historia, la geografía y las circunstancias nos determinan

(15) la violencia alcanza niveles nunca antes vistos

(16) la paz, además de construirla en los hechos, debe alojarse en la mente e imaginación de los seres humanos

(17) el calentamiento global no espera.

(18) los grandes países contaminantes y emisores de carbono, asuman allí sus responsabilidades hacia la humanidad

En las cláusulas transitivas, cuando el Actor está representado por el hablante más otros en el sistema de PERSONA INTERACTUANTE, las Metas son o entidades abstractas, como en (19), o construcciones metafóricas léxicas, como en (20):

(19) Impulsamos el crecimiento económico, la apertura comercial, la responsabilidad ambiental y la transparencia política en un marco de libertades públicas.

(20) La batalla contra el narcotráfico sólo podremos ganarla con coordinación y cooperación global y una revisión profunda de las estrategias seguidas hasta ahora, muchas de ellas incompletas o fallidas 
Esto indica que, cuando no se recurre a la intransitividad como recurso lingüístico de encubrimiento de responsabilidades, se difuminan las Metas de las cláusulas transitivas que sí implicarían un cambio en el estado de cosas con el fin de difuminar la ocurrencia real de estos eventos. Nótese además que el verbo en el ejemplo 19 tiene aspecto imperfectivo, es decir, la acción se está desarrollando en el presente pero no se ha acabado, y en el 20 el verbo está en tiempo futuro, es decir, la acción no se ha realizado. Puede afirmarse, por tanto, que en todo el discurso no hay ninguna acción que sea realizada por la presidenta Chinchilla, a pesar de que el discurso cuente con un número elevado de cláusulas materiales.

\subsubsection{La construcción de las cláusulas relacionales en el discurso}

Las cláusulas relacionales sirven para caracterizar e identificar una entidad:

(i) caracterización:

(22) la trilogía de juventud como acicate, paz como entorno, y desarrollo como meta, es básica para un mundo mejor

(23) los retos de la gobernanza global son muchos

(ii) identificación

(24) educar para la paz es vacunar contra la guerra

(25) Costa Rica, además de anfitriona de la conferencia que aprobó la Convención Americana de Derechos Humanos, en 1969, fue el primer país en ratificarla

A diferencia de las cláusulas materiales, modelan la experiencia como un proceso de "ser" que se desarrolla inertemente, sin necesidad de ninguna fuente de energía. Por ejemplo, la locación estática en el espacio tiende a construirse relacionalmente. Además, en estas cláusulas, el peso experiencial reside en los participantes: el proceso es meramente una unión de tipo muy generalizado entre ellos (el verbo ser o estar cumplen una función similar a un signo de igual). Consecuentemente, el hecho de que aparezca un porcentaje tan alto (36\%) de estas cláusulas en el discurso hace que los destinatarios tengan la sensación de que no está ocurriendo nada realmente.

Como establecen una relación de ser entre dos entidades, necesariamente involucran dos participantes, los cuales, además de cosas y personas, pueden ser también frases nominales o frases verbales. Este tipo de participantes abunda en el discurso analizado y la implicación más importante es que las nominalizaciones son mucho menos explícitas que las cláusulas construidas como la configuración de un proceso. En otras palabras, las nominalizaciones, siendo metáforas gramaticales que estructuran metafóricamente una acción en términos de una entidad, son inherentemente más abstractas que los verbos y en cuanto tales también cumplen el objetivo de la función estratégica de tergiversación. Considérese además que los sustantivos son más estables temporalmente que los verbos, y en cuanto tales más estáticos, pues denotan entidades y no procesos de devenir, o procesos de cambios en el tiempo. Por ejemplo, en el ejemplo 22 se dice lo que es básico para un mundo mejor pero no se indica qué hay que hacer para conseguirlo; paralelamente, en el 23 se cuantifican los retos de gobernanza global pero no se indica cómo vencerlos o enfrentarlos. En la Figura 1, se muestra cómo puede perderse información al utilizar frases nominales o verbales en lugar de cláusulas: 


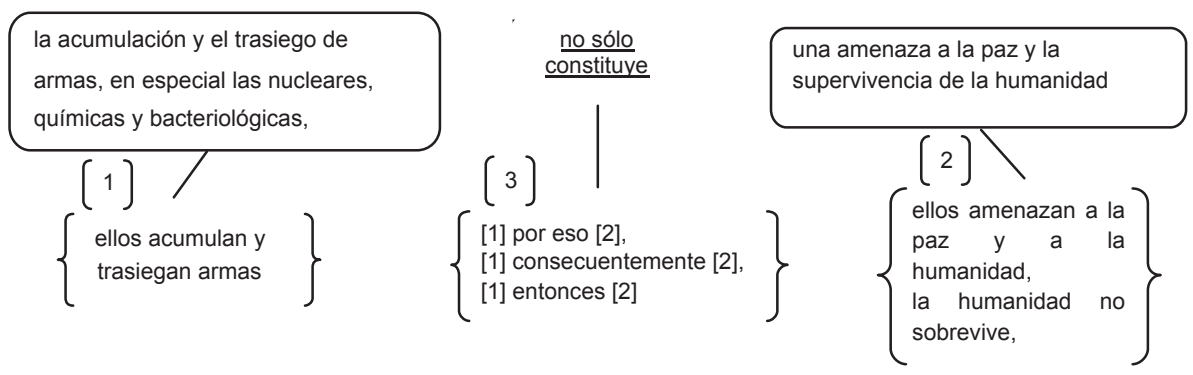

Figura 1. La pérdida de información en la metáfora gramatical

En la metáfora gramatical, un dominio se construye en términos de otro dominio (Halliday y Matthiessen 2006). Para utilizar el ejemplo de la Figura anterior, la construcción ellos acumulan y trasiegan armas es la configuración de un proceso y un participante, es decir, pertenece al dominio de una figura, mientras que la reconstrucción metafórica, la acumulación y el trasiego de armas, en especial las nucleares, químicas y bacteriológicas, se encuentra en el dominio de un elemento, pues constituye un participante representado por una cosa. Al eliminar la construcción de proceso+participante, se esconde al responsable de acumular y trasegar armas. Igualmente, la construcción metafórica una amenaza a la paz y la supervivencia de la humanidad constituye el dominio de un participante y es mucho menos explícita que la figura correspondiente determinada por los procesos amenazar y sobrevivir. Luego, la expresión completa de cláusula como una relacional, la acumulación y el trasiego de armas, en especial las nucleares, químicas y bacteriológicas, no sólo constituye una amenaza a la paz y la supervivencia de la humanidad, no especifica los términos de la relación entre los participantes nominalizados, como en la posible variante ellos acumulan y trasiegan armas por eso ellos amenazan a la paz y a la humanidad. Esta construcción lingüística concreta la función estratégica de tergiversación, puesto que provee información cuantitativamente inadecuada y omite de la referencia directa a los agentes o actores de estas acciones.

En la mayoría de las cláusulas relacionales de este discurso, que ya de por sí abundan, se emplea la construcción de participantes en la forma de frases nominalizadas que, aparte de la elisión de información, prescinden de la configuración de la experiencia con otros procesos que implican cambios y acciones. Esta característica provoca que el discurso sea en gran parte descriptivo.

\subsubsection{La construcción de cláusulas mentales en el discurso}

Las cláusulas mentales, que en este discurso sólo representan el 17\%, construyen gramaticalmente la experiencia que ocurre en el interior de la conciencia, por lo cual el participante que experimenta el proceso, llamado Experimentador, suele ser una entidad consciente. Anteriormente se vio que este tipo de cláusulas aparece al inicio del discurso como una estrategia para expresar la intención del hablante y legitimar el discurso, pues las cláusulas mentales dan significado a la experiencia interna, y esta suele ser la del hablante. Por lo tanto, para analizar estas cláusulas vale la pena fijarse en quiénes son los participantes.

En los siguientes cuatro ejemplos, se ha marcado al Experimentador del Proceso mental con cursiva. Nótese que representa a la primera persona plural, es decir, al hablante + otros en el sistema de PERSONA INTERACTUANTE. Pero más importante aún, el 
participante que representa aquello que es sentido, pensado, deseado o percibido por el Experimentador, llamado el Fenómeno (subrayado), indica personas concretas. Y son estos unos de los pocos casos en que el discurso no sólo se refiere a entidades concretas, sino que los especifica como personas. En otras palabras, el discurso únicamente habla de participantes no abstractos cuando se trata de participantes relacionados con un proceso mental, que no presupone cambios en el universo de los acontecimientos:

(26) nos inspiran los jóvenes, trabajadores y campesinos con oportunidades de vida digna; las mujeres que disfrutamos el pleno ejercicio de la igualdad; los profesionales, científicos y empresarios que innovan y generan riqueza

(27) nos angustian las madres jefas de hogar que apenas pueden alimentar a sus hijos

(28) nos inquietan los adultos mayores que envejecen con privaciones y en soledad; los niños que viven en un vacío de afectos y estímulos; los agricultores que pierden sus cosechas por falta de mercados, crédito o buenas leyes

(29) nos indigna que, aun hoy, haya mujeres a la espera de ser lapidadas, pueblos ahogados por la barbarie del genocidio, y armas nucleares que se acumulan mientras los graneros se vacían

En el resto de las instancias, el Experimentador de los procesos mentales sigue siendo el hablante más otros y se tiende al uso de verbos de significado negativo como sufrir:

(30) mi país y Centroamérica sufrimos con creciente rigor los embates de los carteles de $\underline{\text { las drogas }}$

El uso de las cláusulas mentales en este discurso puede relacionarse con la victimización del Experimentador, el cual representa al hablante + otros y también es un recurso lingüístico, como ya se ha mencionado, que apunta a la función estratégica de legitimación.

Es importante recalcar que la referencia a personas concretas sólo ocurre en concomitancia con el uso de cláusulas mentales que implican, por su naturaleza, un nivel de abstracción mayor que las materiales, y por tanto contribuyen a la tergiversación del discurso.

\section{Conclusiones}

De acuerdo con el análisis de este discurso, se concluye en primer lugar que hay una manipulación de ciertos temas frente a otros. El objetivo parece ser el de exaltar o reforzar ante los ojos de la audiencia las acertadas tomas de decisiones y cursos de acción emprendidos por el gobierno costarricense. La segunda función discursiva del nosotros exclusivo es la de victimización e involucramiento en un contexto de peligro potencial, el de la narcoactividad.

La configuración experiencial del discurso se caracteriza por la presencia considerable de procesos materiales y relacionales. Por la gran cantidad de instancias materiales, se esperaría que el texto implicara hechos y sucesos, pero a rasgos generales más bien da la impresión de ser un discurso inactivo y descriptivo en el cual no se tocan eventos ni cambios ni se perciben participantes concretos. Esto obedece a los significados de los verbos empleados, pues no son prototípicamente materiales, por lo cual no implican un cambio en el estatus de las cosas, y a la poca transitividad de los mismos. Es importante mencionar que la estrategia discursiva detrás de la escogencia de procesos materiales, aunque no sean prototípicos, es que estas son las 
cláusulas más accesibles para la reflexión consciente, pues representan un cambio en el mundo exterior, supuestamente tangible. El hecho de que aparezcan tantas cláusulas relacionales también contribuye a esta sensación de acontecimientos inertes. Además la construcción de estas a partir de reconstrucciones gramaticales metafóricas, en las cuales los procesos son semánticamente vacíos y los participantes frases nominalizadas, provoca que el discurso en sí sea más inexplícito y abstracto.

En cuanto a la relación entre las metafunciones y las funciones discursivas, la siguiente tabla presenta los resultados arrojados por este análisis:

Tabla 5. Estructuras lingüísticas vinculadas con las funciones estratégicas

\begin{tabular}{|c|c|c|c|}
\hline & \multicolumn{3}{|c|}{ ESTRUCTURAS LINGÜÍSTICAS (MICRONIVEL) } \\
\hline & $\begin{array}{l}\text { METAFUNCIÓN } \\
\text { TEXTUAL }\end{array}$ & $\begin{array}{l}\text { METAFUNCIÓN } \\
\text { INTERPERSONAL }\end{array}$ & $\begin{array}{l}\text { METAFUNCIÓN } \\
\text { EXPERIENCIAL }\end{array}$ \\
\hline \multicolumn{4}{|l|}{$\begin{array}{l}\text { FUNCIONES } \\
\text { ESTRATÉGICAS } \\
\text { (MACRONIVEL) }\end{array}$} \\
\hline coerción/resistencia & $\begin{array}{l}\text { tematización o } \\
\text { topicalización }\end{array}$ & $\begin{array}{l}\text { actos de habla } \\
\text { directivos }\end{array}$ & - \\
\hline $\begin{array}{l}\text { legitimación/ } \\
\text { deslegitimación }\end{array}$ & - & $\begin{array}{l}\text { uso de nosotros } \\
\text { inclusivo/exclusivo }\end{array}$ & $\begin{array}{l}\text { escogencias léxicas } \\
\text { cláusulas mentales } \\
\text { metáforas de recipiente }\end{array}$ \\
\hline $\begin{array}{l}\text { representación/ } \\
\text { tergiversación }\end{array}$ & - & - & $\begin{array}{l}\text { metáforas } \\
\text { nominalización } \\
\text { cláusulas intransitivas } \\
\text { pseudo-materiales } \\
\text { cláusulas relacionales } \\
\text { con nominalizaciones } \\
\text { cláusulas materiales con } \\
\text { metas abstractas } \\
\text { cláusulas mentales }\end{array}$ \\
\hline
\end{tabular}

Es la función estratégica de representación/tergiversación la que presenta el mayor número de distintas representaciones lingüísticas en el texto, seguida por la de legitimación/ deslegitimación. La totalidad de recursos lingüísticos que realizan la función de tergiversación ocurren en la metafunción experiencial, es decir, se concretizan lingüísticamente por medio de los niveles sintáctico y semántico. A través de un análisis de este tipo se logra ofrecer a los lectores una interpretación del mundo conceptual que construye el discurso en cuestión, mostrando cuáles temas sobresalen, cuales se ocultan y por qué se ocultan. Cabe resaltar, por último, que las escogencias lingüísticas presentes en el discurso no son casuales, sino que el discurso pone en práctica una serie de funciones estratégicas de manipulación y ejercicio del poder a través de estas escogencias.

\section{Notas}

1. Los términos que se presentan en el presente artículo para referirse a las funciones estratégicas propuestas por Chilton y Schäffner son traducciones propias de las autoras para los términos propuestos por los autores en el texto original a saber: coercion and resistance, legitimization and delegitimization, representation and misrepresentation. 
2. La negrita es añadida.

3. Una copia del discurso presidencial se encuentra disponible en: http://www.nacion.com/2010-09-24/ Opinion/Foro/Opinion2532745.aspx.

4. Como se verá más adelante, los procesos mentales constituyen procesos que toman lugar en el mundo interno de la conciencia, como pensar, sentir, querer, etc.

5. En los ejemplos de (1) a (21) el Proceso está marcado con negrita, el Actor con cursiva (si está explícito) y la Meta subrayada.

\section{Bibliografía}

Chilton, P. y C. Shäffner. 2006. "Discourse and Politics”. En: van Dijk (Ed.), 303-330.

Chinchilla, L. 2010. "La batalla contra el narcotráfico nos exige mucho más". La Nación (Opinión). 24/09. http://www.nacion.com/2010-09-24/Opinion/Foro/Opinion2532745. aspx

Flórez-Estrada, M. 2010. "La campaña de Laura Chinchilla y las mujeres ¿oportunismo o compromiso con un nuevo pacto sexual?". Revista de Ciencias Sociales. 130: 85-99.

Givón, T. 1984. Syntax: A functional-typological introduction. Vol. 1. Amsterdam: John Benjamins.

Halliday, M.A.K. 1973. Explorations in the functions of language. London: Arnold. 2004. An Introduction to Functional Grammar. London: Hodder Headline Group.

Halliday M.A.K. y C. Matthiessen. 2006. Construing experience through meaning: a language-based approach to cognition. London: Continuum.

Lakoff, G. y M. Johnson. 1998. Metáforas de la vida cotidiana. Madrid: Cátedra.

van Dijk, T. 1997. Racismo y análisis crítico de los medios. Barcelona: Paidós.

2006. Discourse Studies, a multidisciplinary introduction. London: Sage. 